\title{
Seasonal prediction of extreme precipitation events and frequency of rainy days over Costa Rica, Central America, using Canonical Correlation Analysis
}

\author{
T. Maldonado ${ }^{1,2,3}$, E. Alfaro ${ }^{1,3,4}$, B. Fallas-López ${ }^{5}$, and L. Alvarado 6 \\ ${ }^{1}$ Center for Geophysical Research, San Jose, Costa Rica \\ ${ }^{2}$ Graduate Program in Atmospheric Sciences, University of Costa Rica, San Jose, Costa Rica \\ ${ }^{3}$ Center for Research in Marine Sciences and Limnology, San Jose, Costa Rica \\ ${ }^{4}$ School of Physics, University of Costa Rica, San Jose, Costa Rica \\ ${ }^{5}$ Costa Rican Electricity Institute, San Jose, Costa Rica \\ ${ }^{6}$ National Meteorological Institute, San Jose, Costa Rica \\ Correspondence to: T. Maldonado (tito.maldonado@ucr.ac.cr, tito.maldonado@cigefi.ucr.ac.cr)
}

Received: 18 May 2011 - Revised: 4 October 2012 - Accepted: 1 October 2012 - Published: 2 April 2013

\begin{abstract}
High mountains divide Costa Rica, Central America, into two main climate regions, the Pacific and Caribbean slopes, which are lee and windward, respectively, according to the North Atlantic trade winds - the dominant wind regime. The rain over the Pacific slope has a bimodal annual cycle, having two maxima, one in May-June and the other in August-September-October (ASO), separated by the midsummer drought in July. A first maximum of deep convection activity, and hence a first maximum of precipitation, is reached when sea surface temperature (SST) exceeds $29^{\circ} \mathrm{C}$ (around May). Then, the SST decreases to around $1^{\circ} \mathrm{C}$ due to diminished downwelling solar radiation and stronger easterly winds (during July and August), resulting in a decrease in deep convection activity. Such a reduction in deep convection activity allows an increase in down welling solar radiation and a slight increase in SST (about $28.5^{\circ} \mathrm{C}$ ) by the end of August and early September, resulting once again in an enhanced deep convection activity, and, consequently, in a second maximum of precipitation. Most of the extreme events are found during ASO. Central American National Meteorological and Hydrological Services (NMHS) have periodic Regional Climate Outlook Fora (RCOF) to elaborate seasonal predictions. Recently, meetings after RCOF with different socioeconomic stakeholders took place to translate the probable climate impacts from predictions. From the feedback processes of these meetings has emerged that extreme event and rainy days seasonal predictions are necessary for
\end{abstract}

different sectors. As is shown in this work, these predictions can be tailored using Canonical Correlation Analysis for rain during ASO, showing that extreme events and rainy days in Central America are influenced by interannual variability related to El Niño-Southern Oscillation and decadal variability associated mainly with Atlantic Multidecadal Oscillation. Analyzing the geographical distribution of the ASO2010 disaster reports, we noticed that they did not necessarily agree with the geographical extreme precipitation event distribution, meaning that social variables, like population vulnerability, should be included in the extreme events impact analysis.

\section{Introduction}

Central America is a region with well-known complex climate variability (Magaña et al., 1999; Alfaro, 2002; Taylor and Alfaro, 2005; Amador et al., 2006). The main precipitation annual cycle in the Pacific slope presents two maxima. The first occurs in May-June (Taylor and Alfaro, 2005), due to the migration to the north of the Intertropical Convergence Zone (ITCZ). Accordingly, the rainy season begins during these months and sea surface temperature (SST) exceeds $29^{\circ} \mathrm{C}$. Hence, deep convection activity develops along with a subtropical lower-tropospheric cyclonic circulation anomaly over the subtropics (Magaña et al., 1999). As convective 
activity diminishes during July and August due to SST decreasing about $1{ }^{\circ} \mathrm{C}$, this cyclonic circulation weakens, corresponding to an anticyclonic acceleration of the low-level flow and, therefore, to an intensification of the trade winds over Central America and the onset of the midsummer drought (MSD) (Magaña et al., 1999). This change in the low-level winds leads to the formation of divergence anomalies that inhibit deep convection activity, and the strengthening of the easterlies that extend up to $700 \mathrm{hPa}$, forcing ascending motion and intense precipitation over the Caribbean side of Central America and subsidence and clear skies on the Pacific side (Magaña et al., 1999). The second absolute maximum peak occurs from August to October (ASO) (Taylor and Alfaro, 2005). During late July and early August there are fewer deep clouds and more incoming solar radiation, heating the SST to above $28^{\circ} \mathrm{C}$. By this time, weakened trade winds and a convergent low-level anomaly lead to enhanced deep convection (Magaña et al., 1999). Normally, this season presents the highest frequency of extreme events in the Pacific slope. The Caribbean slope contrasts this behavior, with decreasing rainfall in ASO, due mainly to the monsoon and a decrement in the strength of the trade winds (Taylor and Alfaro, 2005; Amador et al., 2006).

The influence of the sea surface temperature (SST) anomalies on the precipitation variability field in Central America has been deeply studied in the last decade. Alfaro (2007) explains that in addition to the main mode of interannual variability in the equatorial Pacific, El Niño-Southern Oscillation, or ENSO (Waylen et al., 1994, 1996a, b), the interannual and decadal variability in tropical Atlantic SSTs should be taken into account for a better explanation of the precipitation variability in Central America (Enfield and Alfaro, 1999; Alfaro, 2000; Gianni et al., 2000, 2001; Enfield et al., 2001; Waylen and Quesada, 2001; Taylor et al., 2002; Spence et al., 2004; Poveda et al., 2006). The variability of deep convection and the strength of the trade winds that interact with the complex topography of the region is modulated by the surrounding warm water pools (Enfield and Alfaro, 1999), with temperatures above $28.5^{\circ} \mathrm{C}$ (Wang et al., 2006), and their gradients around the isthmus. Also, variability in SSTs around Central America modifies some key climate features of the overlying atmospheric circulation, such as the Caribbean Low Level Jet at the Intra-American Seas (Amador, 1998; Poveda and Mesa, 1999; Wang, 2007) and Hadley cell (Wang, 2006).

In Central America, Regional Climate Outlook Fora (RCOF) have taken place for the precipitation accumulate prediction in MJJ, ASO and DJFM seasons (Donoso and Ramírez, 2001). Participating in these fora are several stakeholders from different socioeconomic sectors such as energy, health, agriculture and civil defense, among others. One of their suggestions is to extend the seasonal precipitation prediction to other variables like frequency of rainy days and extreme events (wet and dry). Using the methodology developed by Gershunov and Cayan (2003), some recent works

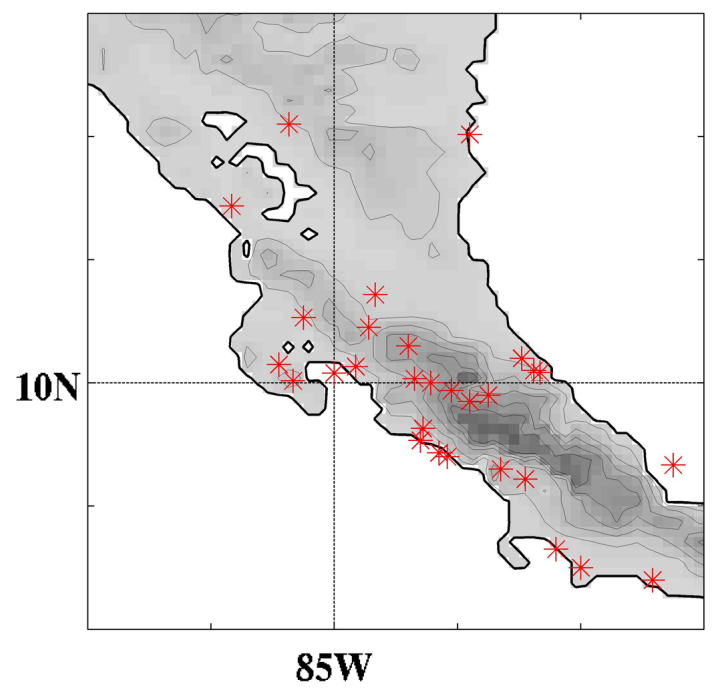

Fig. 1. Red asterisks represent the positions of the stations used. Contours associated with 0, 300, 700, 1100, 1500, 1900 and $3000 \mathrm{~m}$ topographic levels were plotted.

by Alfaro (2007) and Fallas López (2009) showed that this suggestion could be tailored for ASO extreme precipitation events over the isthmus using Canonical Correlation Analysis (CCA) with a SST field as predictor. Their works showed that CCA gives good skill results for prediction of different precipitation aspects during ASO for several regions in Central America.

In this context, the objective of this work is to build skillful CCA prediction models for the ASO season using as predictands monthly precipitation accumulates (ACM), frequency of rainy days (FRD), percentage of days exceeding the 80th percentile or $\mathrm{p} 80$ (wet extremes) and percentage of days that do not exceed the 10th percentile or p10 (dry extremes) over Costa Rica, Central America. We used first the 90th percentile as the wet extreme threshold to allow a symmetrical distribution, but it produced time series with an important number of zeros in almost all the stations. The use of the 80th percentile did not present that problem and better represented the monthly and seasonal ASO variability of days with an important amount of precipitation accumulated. In Sect. 2 is described some relevant features for models construction using CCA. Section 3 presents the main results and Sect. 4 includes qualitative forecasts verification for ASO 2010 season, considering also a summary of national press impact and disaster reports.

\section{Construction of the models}

Basically, the models were built in the same way as Gershunov and Cayan (2003). SST from Smith et al. (2008) was used as predictor, enclosing $63^{\circ} \mathrm{N}-10^{\circ} \mathrm{S}$ and $160^{\circ} \mathrm{E}-15^{\circ} \mathrm{W}$, an area covering almost all North-Tropical eastern Pacific 


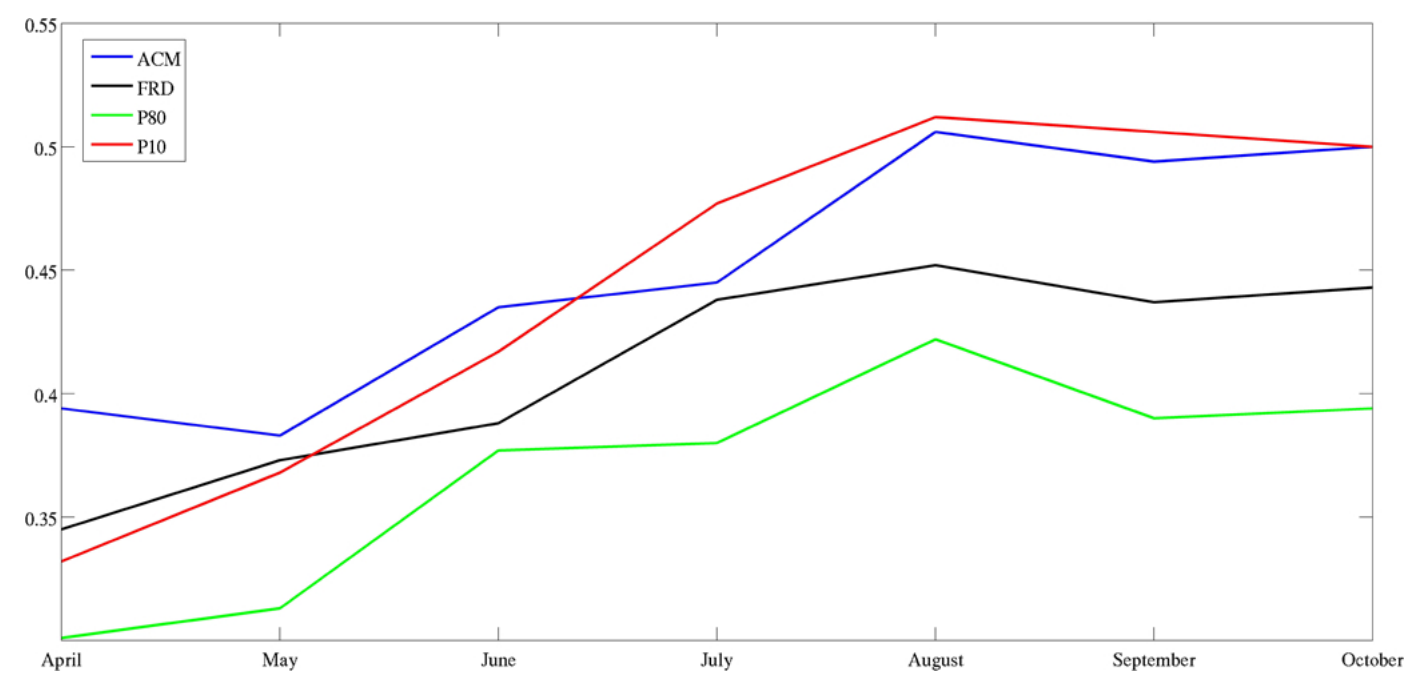

Fig. 2. Spatial skill average $(R)$ of each model. To calculate this skill, first, for each station (observed time series), complete times series are estimated using a cross-validation model, with 1-month window length from 1969 to 2008. Then, Pearson correlation coefficients are calculated between the estimated time series and the observed time series. After that, the average of these coefficients is calculated. SSTs from April to July (classic prognosis scheme lead times) and from August to October (perfect prognosis scheme lead times) were analyzed to determine which month has the best skill for the quarter.
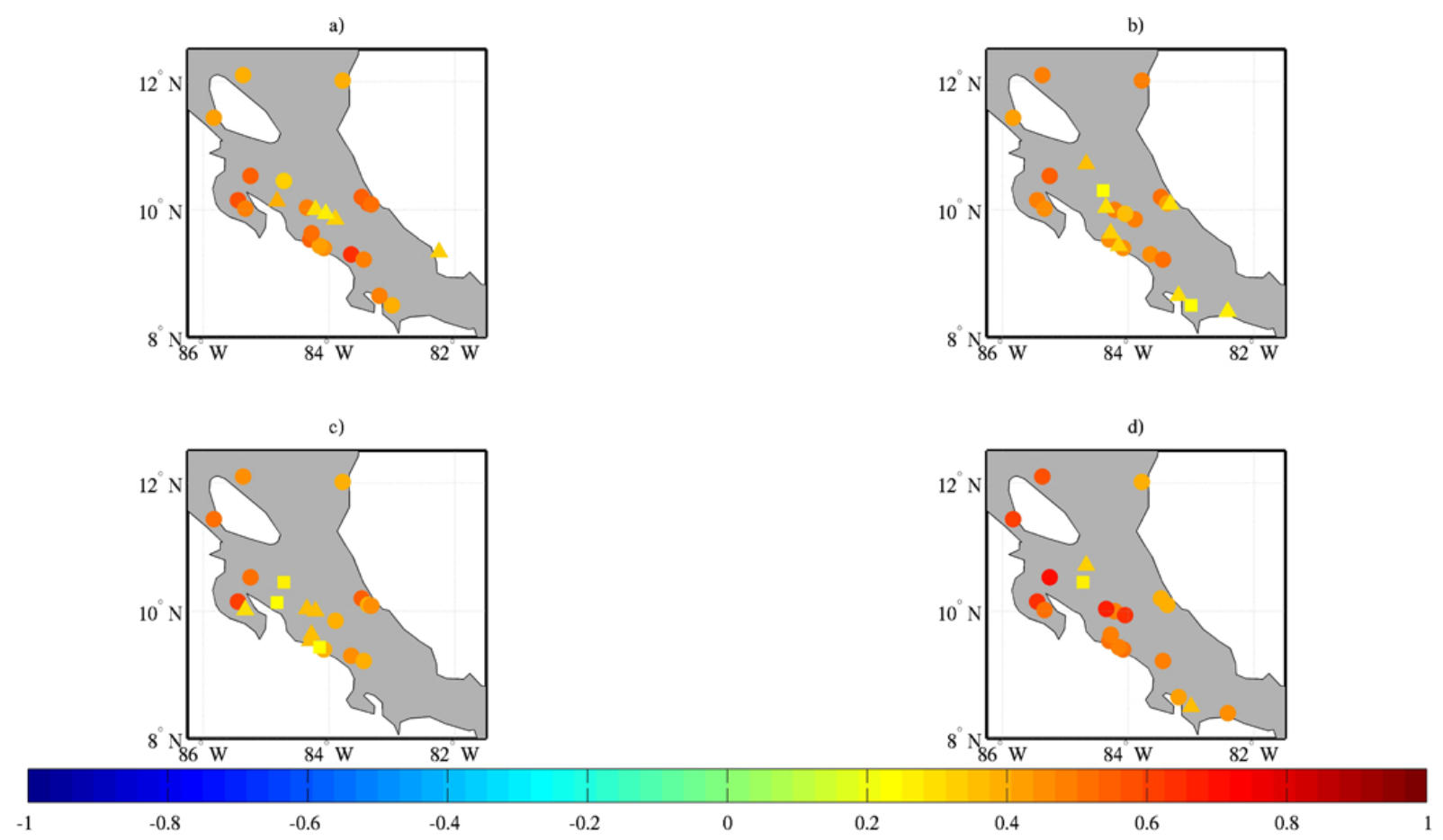

Fig. 3. Spatial skill distribution ( $R$ ) for (a) ACM, (b) FRD, (c) P80, (d) P10 in Costa Rica for the ASO prediction using July SST field as predictor. This skill was calculated as the correlation between the observed time series and those predicted by the model using cross validation (1-month window length from 1969 to 2008). Statistical significance is between 90-95\% (triangles, 5< $\alpha<10 \%$ ), 95-99\% (squares, $1<\alpha<5 \%$ ) and greater than $99 \%$ (circles, $\alpha<1 \%$ ). Significance was calculated according to Davis (1976).

Ocean, all the Caribbean Sea, Gulf of Mexico and part of North-Tropical Atlantic Ocean. This SST area was chosen for this study because it includes important modes of ocean variability such as El Niño-Southern Oscillation, Pacific
Decadal Oscillation and Atlantic Multidecadal Oscilation. Monthly SST fields from April to October 2010 were analyzed as potential predictors; thus, 4 months before the quarter were studied for a classic prognosis scheme, and also each 


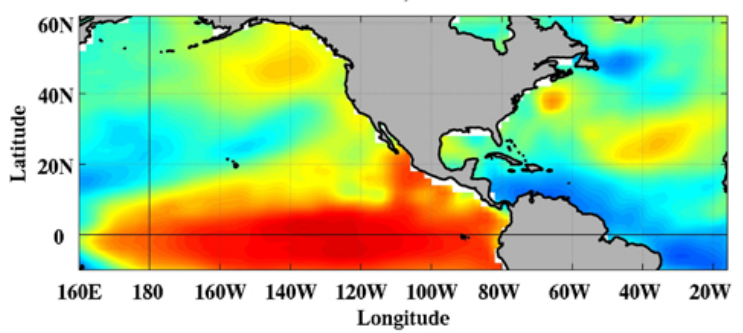

c)

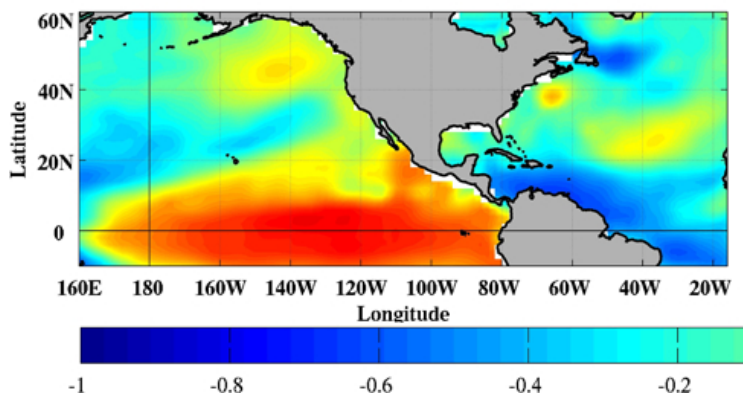

b)

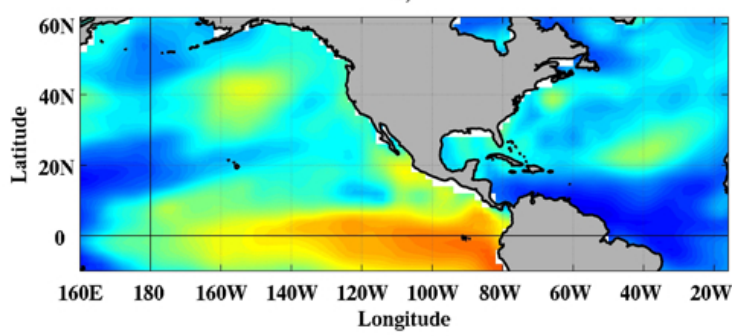

d)

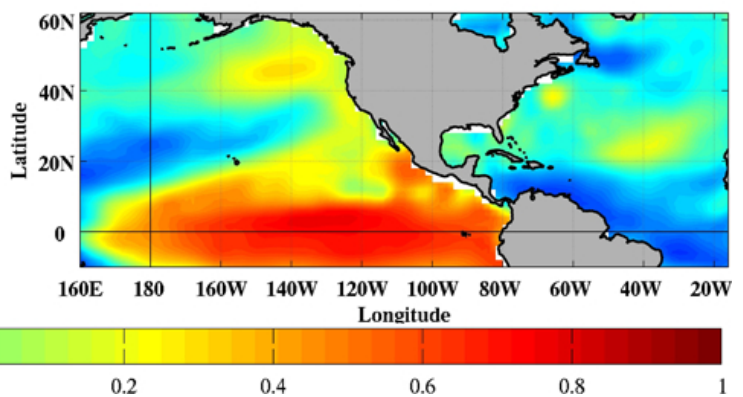

Fig. 4. July SST spatial loadings (mode 1) of each model: (a) ACM, (b) FRD, (c) p80 and (d) p10.

a)
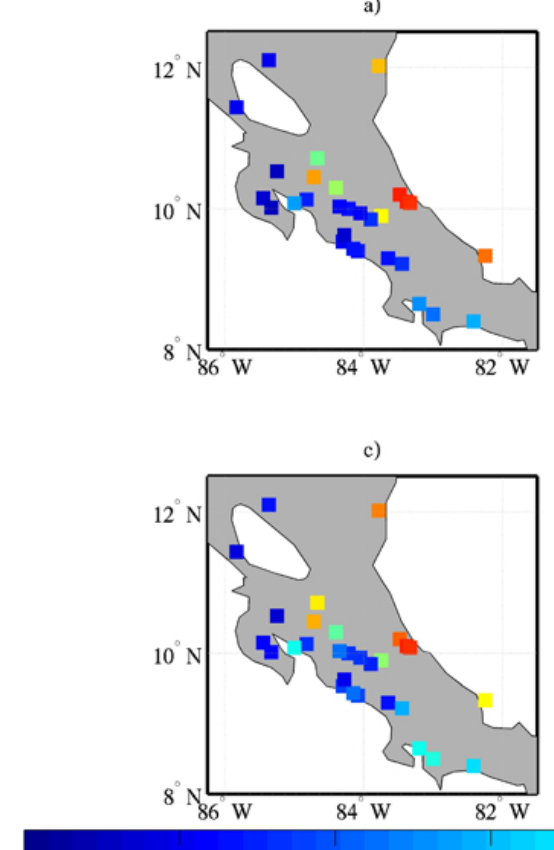

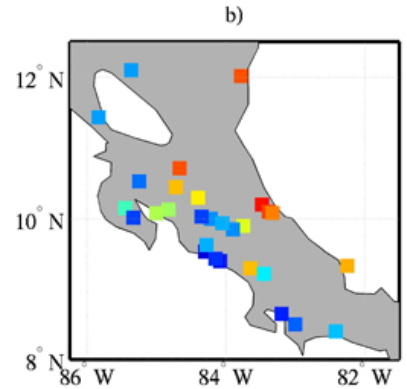

d)

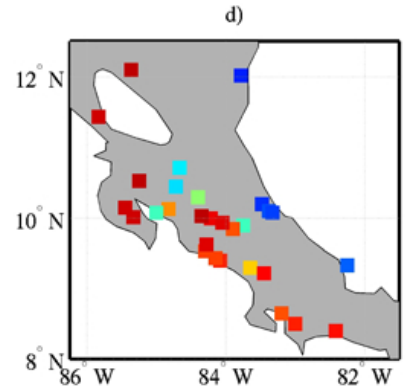

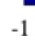

$-0.8$

$-0.6$

$-0.4$

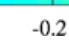

0.2

0.4

0.6

0.8

Fig. 5. ASO predictant spatial loadings (mode 1) of each model: (a) ACM, (b) FRD, (c) p80 and (d) p10.

month of the quarter for a perfect prognosis scheme (lead time). Each model was allowed to range $1<p<P$ EOF patterns in the predictor and also in the predictant field and $1<q<p$ CCA paired modes relating them, where $P=17$ was chosen as the maximum reasonable number of patterns. This threshold was selected to avoid over parameterization in the models, as is indicated by Gershunov and Cayan (2003) and Alfaro (2007). To optimize the models (that is, the best mode combination), the spatial skill average $(R)$ was computed. To calculate this skill, first, for each station (observed time series), complete times series were estimated using a cross-validation model (Wilks, 2006), with 1-month window 


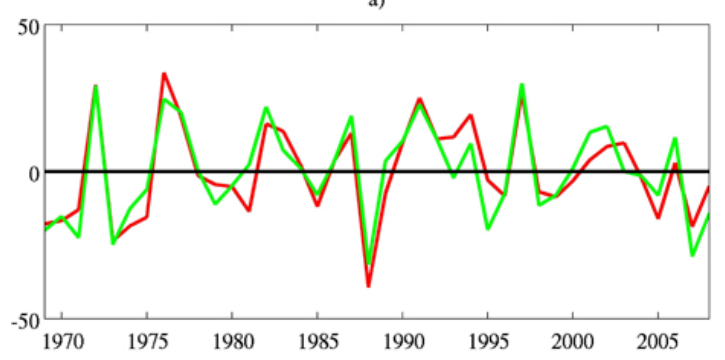

c)

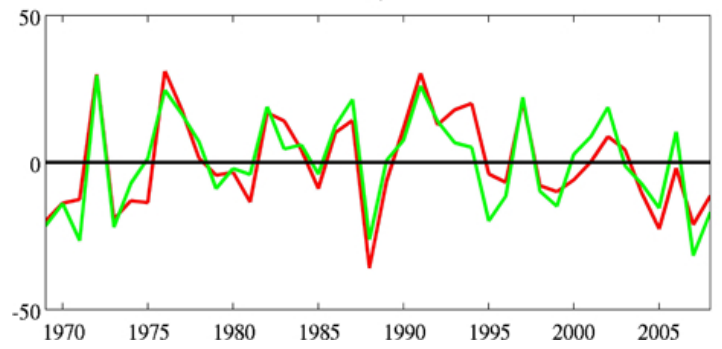

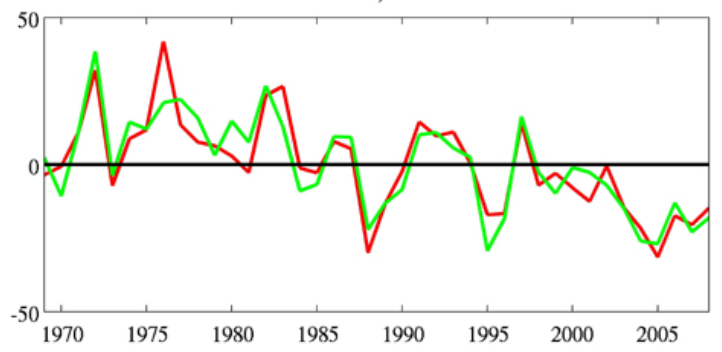

d)

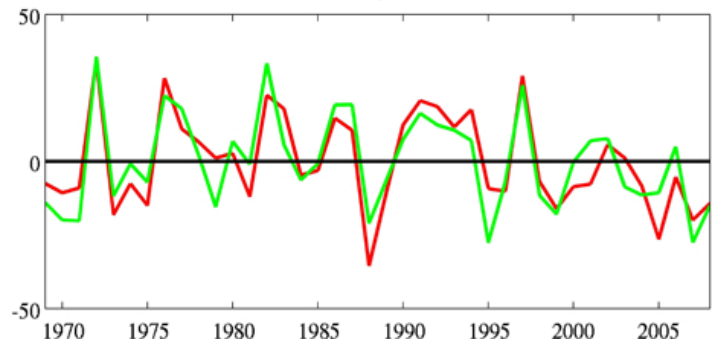

Fig. 6. Normalized time series for mode 1, from 1969 to 2008. (a) ACM, (b) FRD, (c) p80, and (d) p10. Red lines are for July SST modes and green lines are for ASO precipitation modes. Canonical correlation of this mode in all the variables was around 0.9 with statistical significance above $99 \%(\alpha<1 \%)$, according to Davis (1976).

Table 1. Correlation among the first mode of all predictor variables (X modes, red lines in Fig. 6) and normalized differences between Niño3 and AMO. All values have a statistical significance above $99 \%(\alpha<0.01)$. Significance was calculated according to Davis (1976).

\begin{tabular}{lr}
\hline Variable (Mode 1) & $R$ \\
\hline ACM & 0.68 \\
FRD & 0.84 \\
P80 & 0.74 \\
P10 & -0.82 \\
\hline
\end{tabular}

length from 1969 to 2008. Then, Pearson correlation coefficients were calculated between the estimated time series and the observed time series (Wilks, 2006). After that, the average of these coefficients was calculated. The maximum value of this final average was chosen as the best mode combination and, consequently, the best model for a specific SST month. So, at the end, models did not necessarily have 17 EOF and CCA modes. Normally the model was fitted with a small number of EOF and CCA modes (see next section). Finally, the spatial skill average of each month was compared to determined which one has the best skill. The CCA tool used was the Climate Predictability Tool or CPT, elaborated by the International Research Institute for Climate and Society (IRI, http://portal.iri.columbia.edu).

A set of daily precipitation data from various hydrometeorological services were collected, but only those station records with at least $60 \%$ of the data present from 1969 to 2008 were used, which is also considered the base period due to the density and quality of data in such a period. A total of 29 stations (located 24 in Costa Rica, 3 in Nicaragua and 2 in Panama, last five near the Costa Rican land boarders) were used. They were considered representative and associated with different Costa Rican climate regions (Fig. 1).

We defined a day as rainy if the observed precipitation in that day had values greater than $0 \mathrm{~mm} \mathrm{day}^{-1}$. Monthly precipitation accumulates (ACM) and frequency of rainy days (FRD) were computed from the daily data base. For these two variables were calculated the seasonal accumulates for ASO to be used as predictant fields. Also, for each month of the quarter, were estimated the percentage of days exceeding the monthly climate 80 th percentile (p80, wet extremes), and the percentage of days below the monthly climate 10th percentile (p10, dry extremes); both quantities were derived from the daily precipitation distribution. The average for ASO of $\mathrm{p} 80$ and p10 were considered also as predictant fields. Finally, the time series were filled using EOFs as suggested by Alfaro and Soley (2009).

\section{Results and discussion}

Figure 2 shows the spatial skill average of the models, lagging the monthly SST from April to October. June and July SST showed similar skill values for all the four predictant fields. These results give an important operational advantage, because RCOFs are celebrated in Central America during July for ASO prediction. It means that forecasters would have June SSTs by July to elaborate the outlook. However, 
Table 2. Relative frequency (\%) contingency tables between the mode 1 of July SST of each model (X mode 1, red lines in Fig. 6) and the normalized difference of Niño3 and AMO indexes. In parentheses are the absolute frequency values. Categories are Below (B), Normal (N) and Above (A). Levels of significance are represented by $* * *>99 \%(\alpha<1 \%)$, ** 95-99\% $(1<\alpha<5 \%)$ and $* 90-95 \%(5<\alpha<10 \%)$.

\begin{tabular}{|c|c|c|c|c|c|c|c|}
\hline \multicolumn{4}{|c|}{ (a) $\operatorname{ACM}\left(\chi^{2}=12.5^{* *}\right)$} & \multicolumn{4}{|c|}{ (b) $\operatorname{FRD}\left(\chi^{2}=34.6^{* * *}\right)$} \\
\hline & B & $\mathrm{N}$ & A & & B & $\mathrm{N}$ & A \\
\hline B & $46(6)$ & $38(5)$ & $15(2)^{* *}$ & $\mathrm{~B}$ & $77(10)^{* * *}$ & $23(3)$ & $0(0)$ \\
\hline $\mathrm{N}$ & $43(6)$ & $43(6)$ & $14(2)^{* *}$ & $\mathrm{~N}$ & $21(3)$ & $64(9)^{* * *}$ & $14(2)$ \\
\hline A & $8(1)^{* * *}$ & $23(3)$ & $69(9)^{* * *}$ & A & $0(0)$ & $15(2)^{* *}$ & $85(11)$ \\
\hline \multicolumn{4}{|c|}{ (c) $\mathrm{P} 80\left(\chi^{2}=19.6^{* *}\right)$} & \multicolumn{4}{|c|}{ (d) $\mathrm{P} 10\left(\chi^{2}=29.9^{* * *}\right)$} \\
\hline & B & $\mathrm{N}$ & A & & B & $\mathrm{N}$ & A \\
\hline B & $54(7)^{* *}$ & $31(4)$ & $15(2)^{* *}$ & $\mathrm{~B}$ & $0(0)^{* * *}$ & $23(3)$ & $77(10)^{* * *}$ \\
\hline $\mathrm{N}$ & $43(6)$ & $50(7)^{* *}$ & $7(1)^{* * *}$ & $\mathrm{~N}$ & $36(5)$ & $50(7)^{* *}$ & $14(2)^{* *}$ \\
\hline A & $0(0)^{* * *}$ & $23(3)$ & $77(10)^{* * *}$ & A & $62(8)^{* * *}$ & $31(4)$ & $8(1)^{* * *}$ \\
\hline
\end{tabular}

Table 3. Relative frequency (\%) contingency tables between higher order modes of July SST of each model (X modes, red lines in Fig. 7) and some SST indexes. In parentheses are the absolute frequency values. Categories are Below (B), Normal (N) and Above (A). Levels of significance are represented by ${ }^{* * *}>99 \%(\alpha<1 \%),{ }^{* *} 95-99 \%(1<\alpha<5 \%)$ and ${ }^{*} 90-95 \%(5<\alpha<10 \%)$.

\begin{tabular}{|c|c|c|c|c|c|c|c|}
\hline \multicolumn{4}{|c|}{ (a) $\mathrm{ACM}(\mathrm{X}$ mode 2$)$ and $\mathrm{AMO}\left(\chi^{2}=15.2^{* * *}\right)$} & \multicolumn{4}{|c|}{ (b) FRD (X mode 3$)$ and PDO $\left(\chi^{2}=15.8^{* * *}\right)$} \\
\hline & B & $\mathrm{N}$ & A & & B & $\mathrm{N}$ & A \\
\hline B & $46(6)$ & $31(4)$ & $23(3)$ & B & $8(1)^{* * *}$ & $31(4)$ & $62(8)^{* * *}$ \\
\hline $\mathrm{N}$ & $50(7)^{*}$ & $43(6)$ & $7(1)^{* *}$ & $\mathrm{~N}$ & $21(3)$ & $50(7)$ & $29(4)$ \\
\hline A & $0(0)^{* * *}$ & $31(4)$ & $69(9)^{* * *}$ & A & $69(9)^{* * *}$ & $23(3)$ & $8(1)^{* * *}$ \\
\hline \multicolumn{4}{|c|}{ (c) FRD $(X$ mode 2$)$ and Niño3 $\left(\chi^{2}=17.9^{* * *}\right)$} & \multicolumn{4}{|c|}{ (d) P10 (X mode 2$)$ and Niño3 $\left(\chi^{2}=7.8^{*}\right)$} \\
\hline & B & $\mathrm{N}$ & A & & B & $\mathrm{N}$ & A \\
\hline B & $77(10)^{* * *}$ & $15(2)^{* *}$ & $8(1)^{* * *}$ & B & $54(7)^{* *}$ & $15(2)^{* *}$ & $31(4)$ \\
\hline $\mathrm{N}$ & $7(1)^{* * *}$ & $50(7)$ & $43(6)$ & $\mathrm{N}$ & $36(5)$ & $43(6)$ & $21(3)$ \\
\hline A & $15(2)^{* *}$ & $38(5)$ & $46(6)$ & A & $8(1)^{* * *}$ & $46(6)$ & $46(6)$ \\
\hline
\end{tabular}

August has the highest value for all the four predictants. It is also important because a perfect prognosis prediction scheme could be explored early in the forecasted ASO season. Crossvalidation (Fig. 3a, b, c, d, hereafter the sequence for ACM, FRD, p80 and p10, respectively, in the figures) showed good spatial skill in most of the stations, the data having statistical significance values above $95 \%$, according to Davis (1976) for all the variables studied.

The number of CCA modes captured in each model were 2, 3, 1 and 2 for ACM, FRD, p80 and p10, respectively. The model choice in every case was the one that had the highest spatial skill average $(R)$. Notice that maximum average spatial skill was achieved by using a small number of CCA modes. This means that simple models were obtained that facilitate their interpretation.

Figure 4 shows that loadings associated with SST mode 1 (X mode 1), correlate positively with equatorial CentralEastern Pacific, and negatively with the Caribbean and North Tropical Atlantic (NTA). However, in the predictant field, loadings of this mode (Y mode 1) presented negative (positive) values for stations in the Pacific (Caribbean) slope for ACM, FRD and p80 (Figs. 5a, b and c), and p10 presented an inverse pattern (Fig. 5d). Similar results were found by Alfaro (2007) and Fallas López (2009) for Central America precipitation accumulates, showing that SST anomalies dipole pattern between equatorial Eastern Pacific and the NTA dominates the rain variability over the isthmus in ASO (e.g. Enfield and Alfaro, 1999). This pattern means, for example, that when equatorial Eastern Pacific SST anomalies tend to be warmer when compared with those at the NTA, the precipitation response over land tends to be associated with drier anomalies over the Pacific slope and wetter over the Caribbean slope. Time series showed mainly interannual variability captured by this first mode (Fig. 6a, b, c, d).

An important aspect is that all the first modes have significant correlation values with the normalized July differences between Niño3 and Atlantic Multidecadal Oscillation (AMO) indexes (Table 1). It means that knowing these 

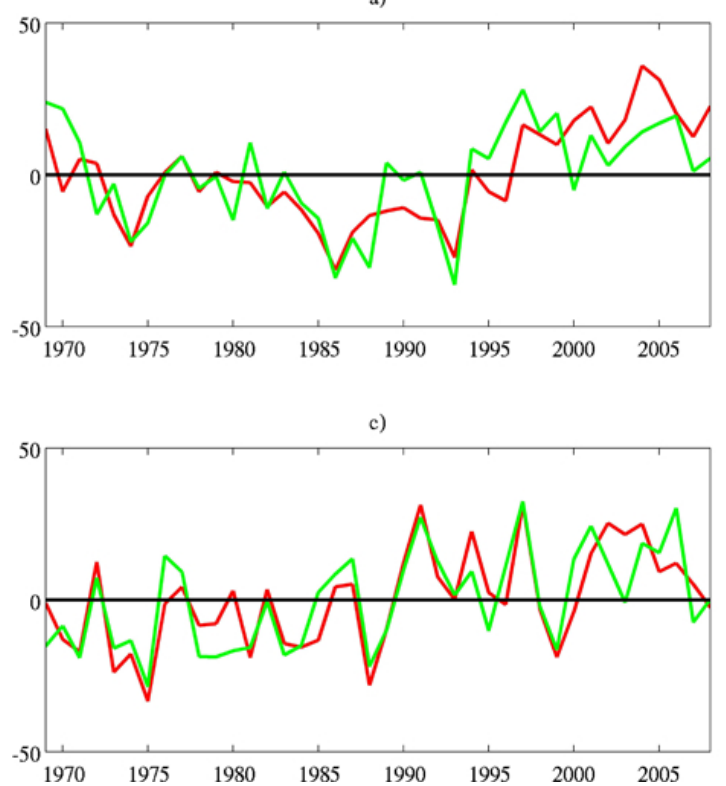
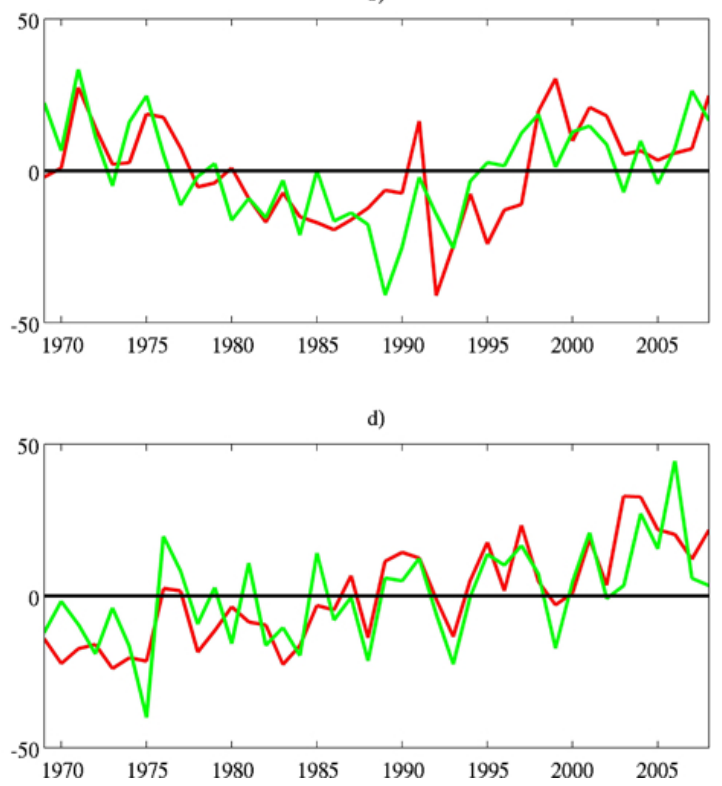

Fig. 7. Normalized time series for high order modes, from 1969 to 2008. (a) ACM mode 2, (b) FRD mode 3, (c) FRD mode 2 and (d) p10 mode 2. Red lines are for July SST modes and green lines are for ASO precipitation modes. Canonical correlation of these modes are 0.7, 0.6, 0.8 and 0.7 , respectively, with statistical significance greater than $99 \%(\alpha<1 \%)$ all of them, except for the latter that has $95 \%(1<\alpha<5 \%)$, according to Davis (1976).

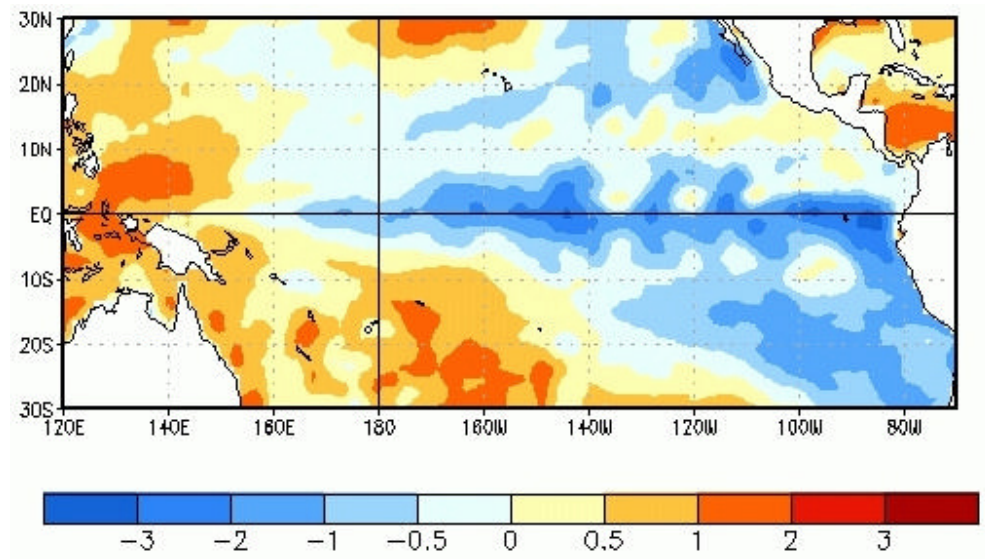

Fig. 8. Average SST anomalies for the week centered on 28 July 2010. Anomalies were computed with respect the 1971-2000 base period weekly means (Xue et al., 2003; http://www.cpc.ncep.noaa.gov/products/analysis_monitoring/enso_disc_aug2010/ensodisc.html).

index predictions, a rule of thumb could be used for ASO precipitation associated predictions. As an example, contingency tables were built between July SST modes from Fig. 6 (red lines) and these indexes (Table 2). These tables show that below (above) normal values tend to be associated with warmer (cooler) SST equatorial Eastern Pacific anomalies when compared with the NTA, for ACM, FRD and p80 modes, while p10 showed the opposite behavior. Notice also that the probability of the opposite scenario is very small.

Times series of second mode in the ACM model (Fig. 7a, July SST) showed mainly multidecadal variability associ- ated with AMO (Table 3a). In general, below (above) normal AMO values tend to be associated with drier (wetter) conditions in Central America. This result agrees with Alfaro (2007). It might reflect the increase (decrease) in the North Atlantic SST and decrease (increase) in vertical wind shear - variability that has a multidecadal scale - which have produced active (poor) hurricane activity over the Atlantic according to Goldenberg et al. (2001). The third mode of the FRD model (Fig. 7b) shows decadal variability related with the Pacific Decadal Oscillation (PDO, Table 3b). The PDO influence over Central America precipitation field 


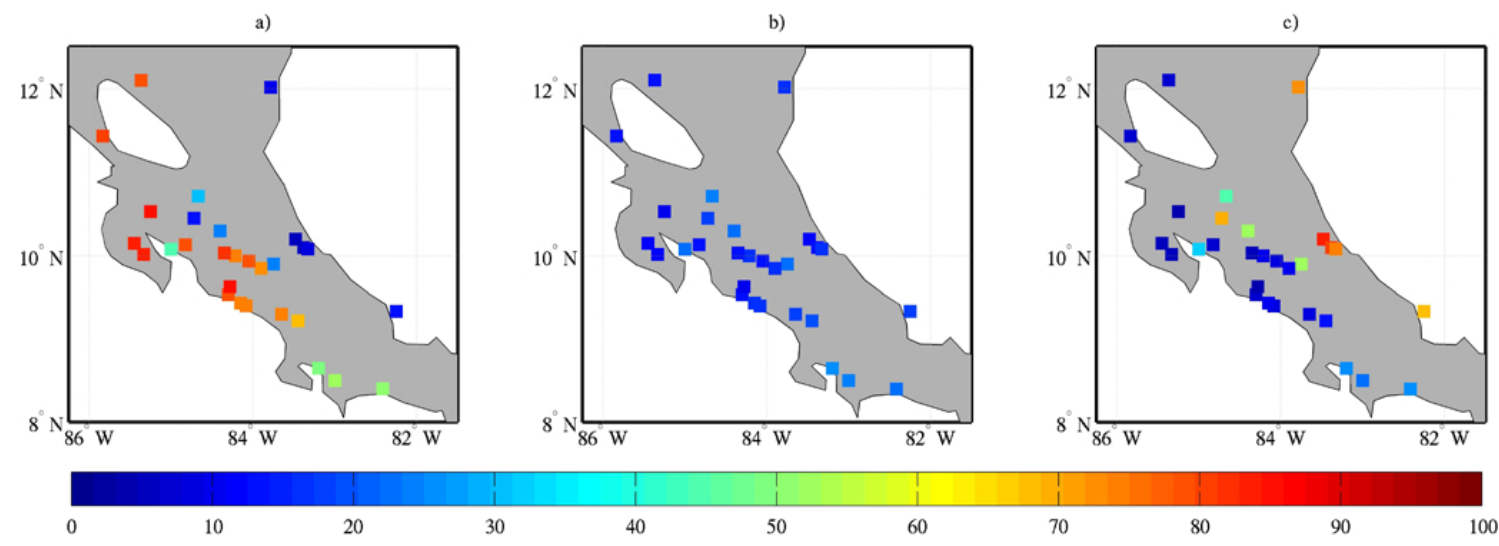

Fig. 9. CCA precipitation forecasts for ASO 2010 accumulates (ACM) using July SST as predictor. Forecast probability maps are for the categories (a) Above, (b) Normal, (c) Below.

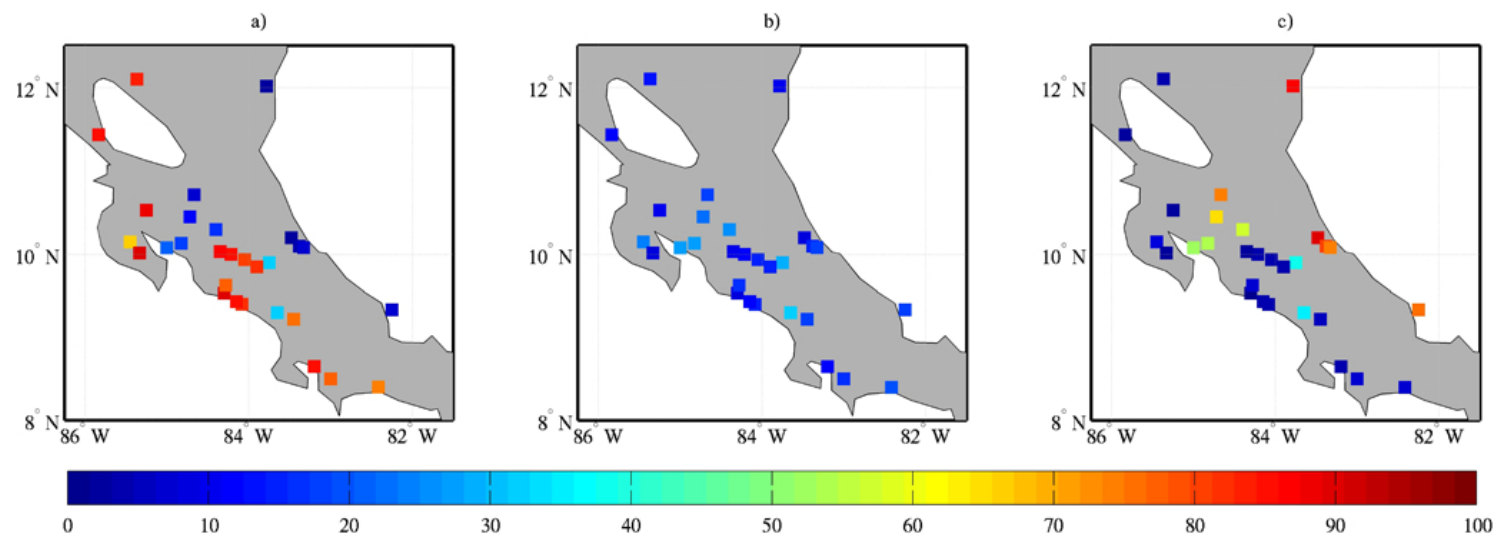

Fig. 10. CCA precipitation forecasts for ASO 2010 frequency of rainy days (FRD) using July SST as predictor. Forecast probability maps are for categories (a) Above, (b) Normal, (c) Below.

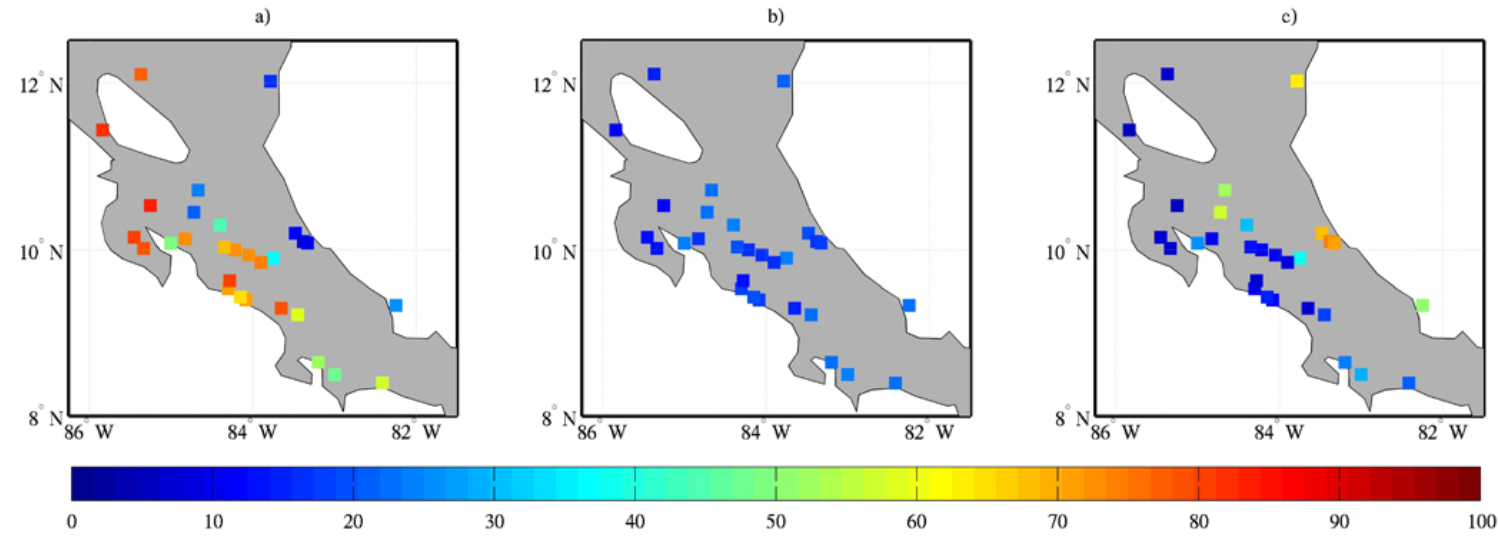

Fig. 11. CCA precipitation forecasts for ASO 2010 percentage of values exceeding the 80th percentile (p80) using July SST as predictor. Forecast probability maps are for categories (a) Above, (b) Normal, (c) Below. 


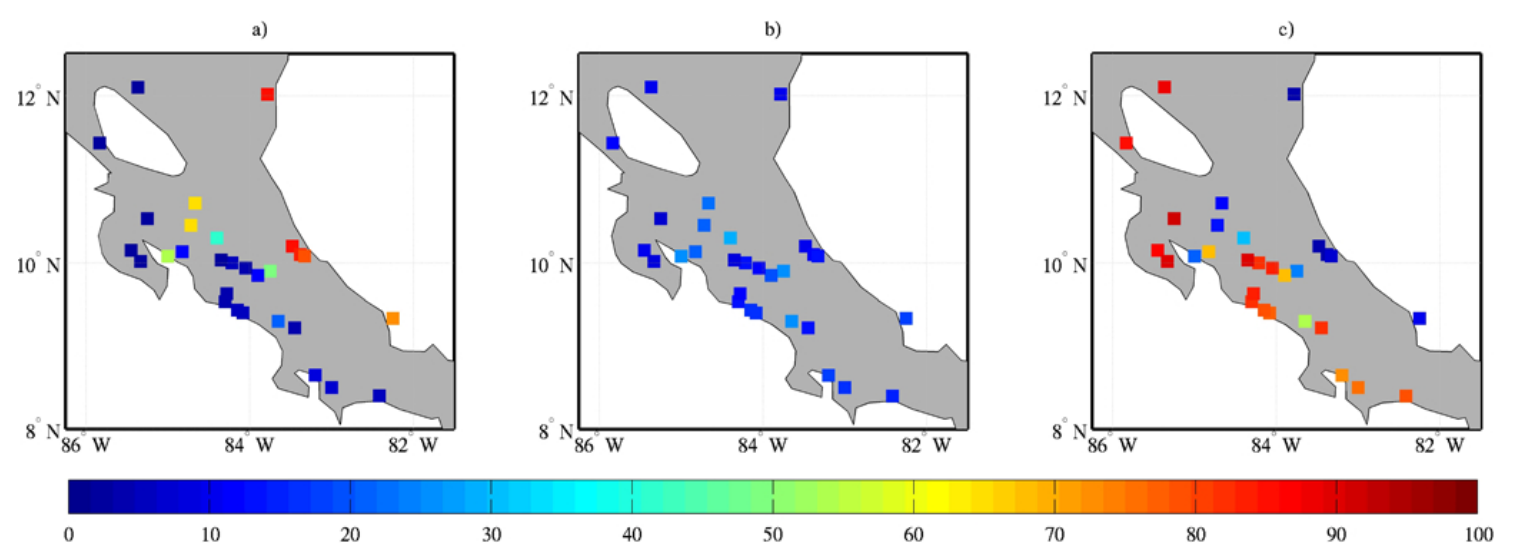

Fig. 12. CCA precipitation forecasts for ASO 2010 percentage of values below the 10th percentile (p10) using July SST as predictor. Forecast probability maps are for categories (a) Above, (b) Normal, (c) Below.

Table 4. Validation of the precipitation accumulates (ACM) forecast for ASO 2010. The observed values were reported by 24 gauge stations from Costa Rican Meteorological and Hydrological Services (Fig. 1). Categories are: Below (B), Normal (N) and Above (A).

\begin{tabular}{lrrrcc}
\hline Station & Longitude & Latitude & $\begin{array}{r}\text { Observed } \\
\text { ACM }(\mathrm{mm})\end{array}$ & $\begin{array}{r}\text { Observed } \\
\text { Category }\end{array}$ & $\begin{array}{c}\text { Forecasted } \\
\text { Category }\end{array}$ \\
\hline CATIE & -83.75 & 9.90 & 786.00 & $\mathrm{~N}$ & $\mathrm{~B}$ \\
Ciudad Quesada & -84.40 & 10.30 & 1314.00 & $\mathrm{~B}$ & $\mathrm{~B}$ \\
Coto 47 & -83.00 & 8.05 & 1651.00 & $\mathrm{~N}$ & $\mathrm{~A}$ \\
Hacienda el Carmen & -83.48 & 10.20 & 845.30 & $\mathrm{~N}$ & $\mathrm{~B}$ \\
Golfito & -83.20 & 8.65 & 1840.00 & $\mathrm{~A}$ & $\mathrm{~A}$ \\
La Argentina & -84.35 & 10.03 & 1200.00 & $\mathrm{~A}$ & $\mathrm{~A}$ \\
La Lola & -83.38 & 10.10 & 729.00 & $\mathrm{~A}$ & $\mathrm{~B}$ \\
Linda Vista & -83.90 & 9.85 & 890.00 & $\mathrm{~A}$ & $\mathrm{~A}$ \\
Llorona & -84.08 & 9.40 & 2405.00 & $\mathrm{~A}$ & $\mathrm{~A}$ \\
Monteverde & -84.83 & 10.13 & 2029.00 & $\mathrm{~A}$ & $\mathrm{~A}$ \\
Nicoya & -85.45 & 10.15 & 1202.00 & $\mathrm{~A}$ & $\mathrm{~A}$ \\
Palo Seco & -84.30 & 9.53 & 2290.00 & $\mathrm{~A}$ & $\mathrm{~A}$ \\
Quepos & -84.15 & 9.43 & 3009.00 & $\mathrm{~A}$ & $\mathrm{~A}$ \\
Repunta & -83.65 & 9.30 & 1370.00 & $\mathrm{~A}$ & $\mathrm{~A}$ \\
Santa Cruz & -85.33 & 10.02 & 944.00 & $\mathrm{~N}$ & $\mathrm{~A}$ \\
Upala & -85.00 & 10.08 & 731.00 & $\mathrm{~B}$ & $\mathrm{~A}$ \\
CIGEFI & -84.05 & 9.94 & 1018.00 & $\mathrm{~N}$ & $\mathrm{~A}$ \\
Aeropuerto Juan Santa Maria & -84.22 & 10.00 & 1072.00 & $\mathrm{~A}$ & $\mathrm{~A}$ \\
San Jorge & -84.67 & 10.72 & 650.00 & $\mathrm{~B}$ & $\mathrm{~B}$ \\
Jilguero & -84.72 & 10.45 & 1516.00 & $\mathrm{~N}$ & $\mathrm{~B}$ \\
Bagaces & -85.25 & 10.53 & 790.00 & $\mathrm{~A}$ & $\mathrm{~A}$ \\
Batan & -83.33 & 10.08 & 527.00 & $\mathrm{~B}$ & $\mathrm{~B}$ \\
Playon & -84.28 & 9.63 & 1949.00 & $\mathrm{~A}$ & $\mathrm{~A}$ \\
Volcan Buenos Aires & -83.45 & 9.22 & 1430.00 & $\mathrm{~N}$ & $\mathrm{~A}$ \\
\hline
\end{tabular}

has already been studied by Mantua and Hare (2002), and recently by Fallas and Alfaro (2012). In a previous study, Fallas López (2009) also found some influence of PDO on several precipitation features in Central America, also in relationship with the ENSO signal.

Meanwhile, time series of second FRD mode (Fig. 7c and Table 3c) and second mode of p10 model (Fig. 7d and Table 3d) showed mainly trend variability. They did not have any significant statistical association with any of the SST indexes used (ENSO, NTA, AMO or PDO) and both trends had a p-value below 0.01 .

\section{Prediction for ASO 2010}

Conditions for SST in July 2010 over the Pacific Ocean and the Caribbean Sea were reported by the Climate 


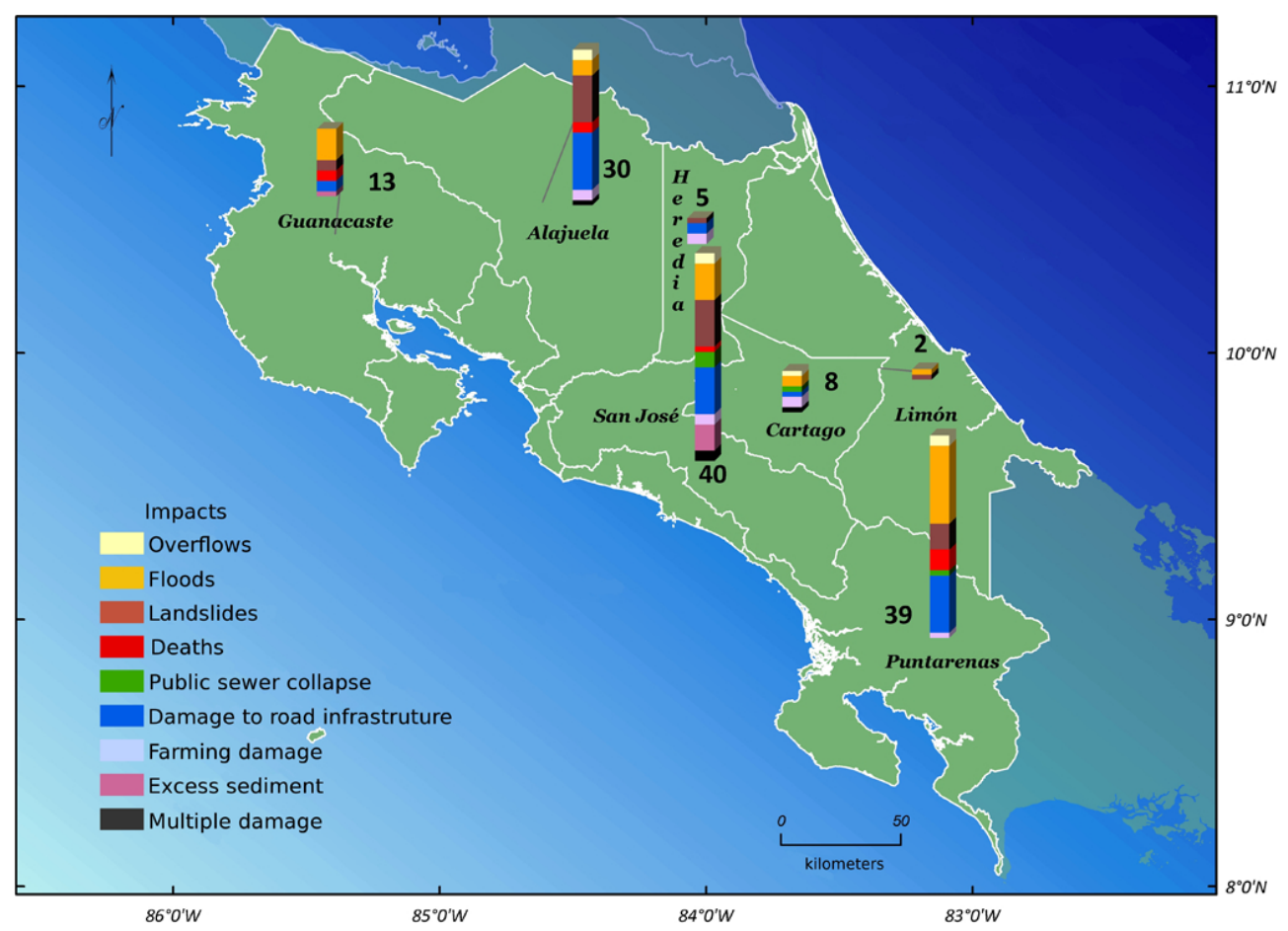

Fig. 13. Spatial distribution, by province, of the impacts and disasters due or related to hydro-meteorological causes during ASO 2010 season. Numbers are the sum of the categories listed. They were compiled from national newspapers of Costa Rica.

Table 5. Contingency table between the ACM observed and the forecasted categories shown in Table 4, during ASO 2010. Categories are: Below (B), Normal (N) and Above (A). Hit Rate: 62.50, Skill Score: 43.80, LEPS: 45.90, Gerrity Score: 62.50, POD B and A: 42.80 and 70.60 and FAR B and A: 25 and 7.7, respectively. Spearman and Kendall correlation values between observed and forecasted categories are 0.56 and 0.53 , respectively, both with pvalues $<0.01$.

\begin{tabular}{cccc}
\hline & $\mathrm{B}$ & $\mathrm{N}$ & $\mathrm{A}$ \\
\hline $\mathrm{B}$ & 3 & 0 & 1 \\
$\mathrm{~N}$ & 3 & 0 & 4 \\
$\mathrm{~A}$ & 1 & 0 & 12 \\
\hline
\end{tabular}

Prediction Center (http://www.cpc.ncep.noaa.gov/products/ analysis_monitoring/enso_disc_aug2010/ensodisc.html). Figure 8 shows the average SST anomalies for the week centered on 28 July 2010. Anomalies were computed with respect to the 1971-2000 base period weekly means (Xue et al., 2003). Warmer temperatures over the NTA when compared with the equatorial Eastern Pacific were observed, so, following the rule of thumb described in the previous section (Table 2), wetter conditions on the Costa Rican Pacific slope and drier conditions in the Caribbean slope were expected.

CCA model forecasts of ACM, FRD and p80 (Figs. 9, 10 and 11) show a scenario with high probability of above (below) normal conditions in the Pacific (Caribbean) slope sta- tions. According to this forecast, we expected values of prediction exceeding not only the monthly accumulates, but also in the amount of extreme wetter events during ASO 2010. Forecast of p10 (Fig. 12) is consistent with the previous results. For p10, low percentage of probability is expected for the above normal scenario over the Pacific, but with high percentage of probability over the Caribbean.

To make a qualitative validation of these forecasts, three bulletins for August, September and October 2010, elaborated by the Costa Rica National Meteorological Institute, were used (IMN, 2010a, b, c, http://www.imn.ac.cr/ boletines/index.html). They analyzed the recorded monthly precipitation for ASO 2010 of the gauge stations around the country. From these reports it was noticed that monthly precipitation values were above the climate mean for stations localized in the Pacific slope and below the mean for stations localized in the Caribbean slope. The monthly precipitation anomaly was decreasing from August to October, each preceding month with greater values of precipitation anomalies than the next. It was reported that regions located near the Pacific showed positive anomalies particularly in August and September. According to IMN (2010a, b, c), among the sources for these very active wet ASO extreme event seasons in the Pacific slope are the persistent cool (warm) anomalies in equatorial Eastern Pacific (North Tropical Atlantic), which were reported as strong Niña events with a warming record on NTA SSTs that enhanced the deep convection, weakening trade winds. The precipitation effects associated 
with easterly waves 37 (20-21 August) and 39 (25 August), tropical storms Matthew (23-24 September) and Nicole (2830 September), and Hurricane Richard (21 October) contributed also to the great number of extreme events observed around the country during the ASO 2010 trimester (IMN, 2010a, b, c).

In Table 4, we show a validation of the monthly precipitation accumulates (ACM) observed in ASO 2010. These data were compiled by Costa Rican National Meteorological and Hydrological Services (IMN and ICE in Spanish). Categorizing the observed data and comparing with the prediction, we observed that most of the stations placed throughout the Pacific slope validated the forecasted category. Table 5 is a contingency table between the observed and the forecasted category. Statistics associated to that table show good validation values for the ASO 2010 prediction in Costa Rica.

Figure 13 shows the spatial ASO distribution of impacts and disasters reports associated with hydro-meteorological causes in Costa Rica. This information was gathered from national newspapers and summarized by province, which is the greatest political division of Costa Rica. The provinces that reported more impacts were San Jose where the capital (also named San Jose) is located and also where the majority of the country's population is living in Pacific Slope counties, Puntarenas (Pacific Coast), and Alajuela (the second province in terms of population, also concentrated in $\mathrm{Pa}$ cific Slope counties). Comparing these reports with the precipitation impacts information in IMN (2010a, b, c) and Table 4 , we noticed that they did not necessarily agree with the geographical extreme event distribution, meaning that social variables, like population vulnerability, should be included in the extreme events impact analysis.

Acknowledgements. The authors would like to recognize the partial support of the following projects during this research: IAI-CRN2050, UCR-VI 805-A7-002, A8-606, A9-532, 808-A9-070. The authors also wish to acknowledge CIGEFI - UCR, IMN and ICE Costa Rica, INETER - Nicaragua and ETESA - Panama. These institutions kindly provided meteorological data. Finally to CIIFEN, who supported and encouraged the publication of these results presented during the International Workshop on ENSO, Decadal Variability and Climate Change in South America, 12-14 October 2010, Guayaquil, Ecuador.

\section{References}

Alfaro, E.: Eventos cálidos y fríos en el Atlántico tropical norte, Atmosfera, 13, 109-119, 2000.

Alfaro, E. J.: Some characteristics of the annual precipitation cycle in Central America and their relationship with its surrounding tropical oceans, Tópicos Meteorológicos y Oceanográficos, 9, 88-103, 2002.

Alfaro, E. J.: Uso del análisis de correlación canónica para la predicción de la precipitación pluvial en Centroamérica, Ingeniería y Competitividad, 9, 33-48, 2007.
Alfaro, E. J. and Soley, F. J.: Descripción de dos métodos de rellenado de datos ausentes en séries de tiempo meteorológicas, Revista de Matemática: Teoría y Aplicaciones, 16, 60-75, 2009.

Amador, J. A.: A climate feature of tropical Americas: the trade wind easterly jet, Tópicos Meteorológicos y Oceanográficos, 5, 91-102, 1998.

Amador, J. A., Alfaro, E. J., Lizano, O. G., and Magaña, V. O.: Atmospheric forcing of the eastern tropical Pacific: A review, Prog. Oceanogr., 69, 101-142, 2006.

Davis, R. E.: Predictability of sea surface temperature and sea level pressure anomalies over the North Pacific ocean, J. Phys. Oceanogr., 6, 249-266, 1976.

Donoso, M. and Ramírez, P.: Latin America and the Caribbean: Report on the Climate Outlook Forums for Mesoamerica, in: Coping with the climate: A step Forward, Workshop Report: A multi-stakeholder review of Regional Climate Outlook Forums, Pretoria, South Africa, 16-20 October 2000, Publication IRICW/01/1, 11-18, 2001.

Enfield, D. B. and Alfaro, E. J.: The dependence of Caribbean rainfall on the interaction of the tropical Atlantic and Pacific oceans, J. Climate, 12, 2093-2103, 1999.

Enfield, D. B., Mestas-Nuñez, A. M., and Trimble, P. J.: The Atlantic multidecadal oscillation and its relation to rainfall and river flows in the continental US, Geophys. Res. Lett., 28, 2077-2080, 2001.

Fallas López, B.: Predicción estacional de los campos de precipitación y temperatura en Centroamérica, usando herramientas estadísticas, Tesis de Licenciatura en Meteorología, Escuela de Física, Universidad de Costa Rica, 50-63, 2009.

Fallas López, B. and Alfaro, E. J.: Uso de herramientas estadísticas para la predicción estacional del campo de precipitación en América Central como apoyo a los Foros Climáticos Regionales. 1: Análisis de tablas de contingencia, Revista de Climatología, 12, 61-80, 2012.

Gershunov, A. and Cayan, D. R.: Heavy daily precipitation frequency over the contiguous United States: sources of climate variability and seasonal predictability, J. Climate, 16, 27522765, 2003.

Gianni, A., Kushnir, Y., and Cane, M. A.: Interannual variability of Caribbean rainfall, ENSO, and the Atlantic ocean, J. Climate, 13, 297-311, 2000.

Gianni, A., Cane, M. A., and Kushnir, Y.: Interdecadal changes in the ENSO teleconection to the Caribbean region and the North Atlantic oscillation, J. Climate, 14, 2867-2879, 2001.

Goldenberg, S. B, Landsea, C. W., Mestas-Nuñez, A. M., and Gray, W. M.: The recent increase in Atlantic Hurricane Activity: Causes and implications, Science, 293, 474-479, 2001.

Instituto Meteorológico Nacional (IMN): Boletín Meteorológico Mensual - Agosto 2010, 35 pp., 2010a.

Instituto Meteorológico Nacional (IMN): Boletín Meteorológico Mensual - Septiembre 2010, 36 pp., 2010b.

Instituto Meteorológico Nacional (IMN): Boletín Meteorológico Mensual - Octubre 2010, 40 pp., 2010c.

Magaña, V., Amador, J., and Medina, S.: The midsummer drough over Mexico and Central America, J. Climate, 12, 1577-1588, 1999.

Mantua, J. M. and Hare, S. R.: The Pacific Decadal Oscillation, J. Oceanogr., 58, 35-44, 2002. 
Poveda, G. and Mesa, O. J.: La corriente de chorro superficial del oeste [del Chocó] y otras dos corrientes de chorro en Colombia: climatología y variabilidad durante las fases del ENSO, Revista de la Academia Colombiana de Ciencias Exactas, Físicas y Naturales, 23, 517-528, 1999.

Poveda, G., Waylen, P. R., and Pulwarty, R. S.: Annual and interannual variability of the present climate in the northern South America and southern Mesoamerica, Palaeogeogr. Palaeocl., 234, 3-27, 2006.

Smith, T. M., Reynolds, R. W., Peterson T. C., and Lawrimore, J.: Improvements to NOAA's Historical Merged Land-Ocean Surface Temperature Analysis (1880-2006), J. Climate, 21, $2283-$ 2296, 2008.

Spence, J. M., Taylor, M. A., and Chen, A. A.: The effect of concurrent sea-surface temperature anomalies in the tropical Pacific and Atlantic on Caribbean rainfall, Int. J. Climatol., 24, 1531-1541, 2004.

Taylor, M. A. and Alfaro, E. J.: Climate of Central America and the Caribbean, in: Encyclopedia of World Climatology, edited by: Oliver, J. E., Springer, The Netherlands, 183-188, 2005.

Taylor, M. A, Enfield, D. B., and Chen, A. A.: The influence of the tropical Atlantic versus the tropical Pacific on Caribbean rainfall, J. Geophys. Res.-Oceans, 107, 10.1-10.14, 2002.

Wang, C.: An overlooked feature of tropical climate: interPacific-Atlantic variability, Geophys. Res. Lett., 33, L12702.1L12702.5, 2006.
Wang, C.: Variability of the Caribbean low-level jet and its relation to climate, Clim. Dynam., 29, 411-422, 2007.

Wang, C., Enfield, D. B., Lee, S.-K., and Landsea, C. W.: Influences of the Atlantic warm pool on western hemisphere summer rainfall and Atlantic hurricanes, J. Climate, 19, 3011-3028, 2006.

Waylen, P. R. and Quesada, M.: The effect of Atlantic and Pacific surface temperatures on the mid-summer drough of Costa Rica, Cuadernos de Investigación Geográfica, 27, 193-205, 2001.

Waylen, P. R., Quesada, M. E., and Caviedes, C. N.: The effects of El Niño-Southern oscillation on precipitation on San José, Costa Rica, Int. J. Climatol., 14, 559-568, 1994.

Waylen, P. R., Caviedes, C. N., and Quesada, M. E.: Interannual variability of monthly precipitation in Costa Rica, Int. J. Climatol., 9, 2606-2613, 1996a.

Waylen, P. R., Caviedes, C. N., and Quesada, M. E.: Temporal and spatial variability of annual precipitation in Costa Rica and the southern oscillation, Int. J. Climatol., 16, 173-193, 1996b.

Wilks, D. S.: Statistical Forecasting, in: Statistical methods in the atmospheric sciences, Academic Press, Elsevier, San Diego, California, 2, 179-254, 2006.

Xue, Y., Smith, T. M., and Reynolds, R. W.: Interdecadal changes of 30-yr SST normal during 1871-2000, J. Climate, 16, 1601-1612, 2003. 